\section{Surgical management of juvenile nasopharyngeal angiofibroma using lateral rhinotomy: study of 80 cases}

\author{
Ninad Gaikwad, Nilam Sathe, \\ Abhijeet Bhatia, Dhanashree Chiplunkar, \\ Manoj Patil \\ ENT Department, KEM Hospital, Mumbai, \\ India
}

Abstract

A series of 80 patients with histopathologically confirmed juvenile nasopharyngeal angiofibroma were treated surgically over a period of ten years (1995-2004). The lateral rhinotomy approach was used to expose the tumor and its extensions. Lateral rhinotomy with its extensions provides wide exposure of and access to the nose, nasopharynx, paranasal sinuses, pterygopalatine fossa, infratemporal fossa and temporal fossa. Most intracranial, extradural extensions can also be approached. There were no major operative or post-operative complications. Longterm follow up from one to ten years showed only 8 recurrences. The added advantage of this approach is that it can be combined with all the other anterior and lateral skull base approaches. The cosmetic outcome is satisfactory if nasal aesthetic subunits are taken into considerations while making the incision. The lateral rhinotomy approach is the most direct route to the body of the tumor and can be used to approach all the possible extensions of the tumor.

\section{Introduction}

Juvenile nasopharyngeal angiofibroma (JNA) is a rare, benign but locally invasive, unencapsulated and highly vascular tumor occurring in adolescent males. Although morphologically and histologically benign, the tumors are highly aggressive and destructive. They may be associated with significant morbidity and occasional mortality. They account for 0.05 to $0.5 \%$ of all head and neck tumors, and are the most common benign tumors of the nasopharynx. ${ }^{1}$

Over the past centurym the treatment of JNA has come back full circle. The early failures of the head and neck surgeons to resect the highly vascular lesion due to the lack of imaging and appropriate anesthesia techniques stimulated interest in alternative methods like radiotherapy, chemotherapy and hor- monal therapy. ${ }^{2}$ None of these proved successful in managing the tumor. However, with the advent of computed tomography (CT), magnetic resonance imaging (MRI), angiography and newer techniques of hypotensive anesthesia, there has been renewed interest in surgical management of JNA.

A number of approaches have been described for the surgical management of JNA. They can be classified primarily as anterior, inferior and lateral skull base approaches. We present our experience with the surgical resection of JNA through the lateral rhinotomy approach. Lateral rhinotomy with its extensions provides wide exposure of and access to the nose, nasopharynx, paranasal sinuses, pterygopalatine fossa, infratemporal fossa and temporal fossa. ${ }^{3,4}$

\section{Materials and Methods}

We carried out a retrospective review of the medical records of 80 patients with histopathologically proven JNA seen between January 1995 to April 2004 at the Department of Otorhinolaryngology of the KEM Hospital, Mumbai. The follow-up period ranged from one to ten years with a median period of 4.3 years. All patients were males except 2 . The average age of presentation was 14.2 years. There were 8 known recurrences with multiple events in 2 patients. All patients were evaluated by contrast CT scan. Pre-operative embolization was used only in 10 patients, but was later abandoned on account of one documented case of blindness during the embolization procedure. Other complications of this procedure, such as transient hemiplegia and transverse myelitis, which have been reported in other series, were not observed.

Surgery was performed with the lateral rhinotomy approach in 74 of the 80 patients. The transpalatal approach was used in 6 patients with small tumors.

\section{Results}

\section{Age and sex}

All patients were of Indian origin. There were 78 males and 2 females; age range 8-27 years, median age 14.2 years. Eighty percent of the patients were aged 14-17 years. The youngest patient was an 8-year old female. The oldest patient was a 27-year old female who presented with stage IV lesion and had to be operated on in collaboration with neurosurgeons.
Correspondence: Nilam Uttam Sathe, Patidar Complex, $3^{\text {rd }}$ Floor, B/ 304, Kannammar Nagar No. 2, Vikhroli (East), Mumbai 400083, Maharashtra, India.

Tel. +91.022.2578.2801. Mob. +91.982 .1309 .298 .

E-mail: drneelam_s@yahoo.co.in

Key words: juvenile nasopharyngeal angiofibroma, lateral rhinotomy, surgical approach.

Conflicts of interests: the authors declare no potential conflicts of interests.

Received for publication: 16 August 2011.

Revision received: 16 August 2011.

Accepted for publication: 21 October 2011.

This work is licensed under a Creative Commons Attribution NonCommercial 3.0 License (CC BYNC 3.0).

(C) Copyright N. Gaikwad et al., 2011

Licensee PAGEPress, Italy

Surgical Techniques Development 2011; 1:e34

doi:10.4081/std.2011.e34

\section{Symptoms and signs}

Nasal obstruction and epistaxis were the most common presentations. The mean duration of symptoms was eight months (range 224 months) (Table 1).

Others symptoms and signs included anosmia, snoring, nasal speech, trismus, mouth breathing, impaired vision, headache and sinusitis.

\section{Staging}

Staging was based on the criteria established by Andrew and Fish. ${ }^{5}$ All patients were evaluated by contrast CT scan of paranasal sinuses. Of the 80 patients in the series, 14 patients were in stage I, 26 were in stage II, 38 were in stage III out of which 30 were in stage III A. One patient was in stage IVA and one was in stage IVB.

\section{Pre-operative procedure}

For each patient, axial and coronal computed tomography (Figures 1 and 2) and nasal endoscopy were performed to define the tumor size and extent. For the majority of cases, the tumor had advanced into the pterygopalatine fossa (80\%), infratemporal fossa (38\%) and the sphenoid sinus (74\%). Intracranial extension was seen in $10 \%$ and orbital involvement in $8 \%$ of the cases. Pre-operative biopsy was obtained only in a few patients where the diagnosis was in doubt.

\section{Surgical procedure}

Of the 80 patients, 74 underwent lateral rhinotomy and the transpalatal approach was adopted in 6. Lip splitting extension was used 
in 20 patients, while 40 patients required the Weber Fergusson's extended incision. Two patients required frontotemporal resection in association with neurosurgeons. ${ }^{6}$ The overall recurrence rate in our series was $10 \%$ ( 8 of 80 patients). Out of these, 4 patients (50\%) patients had intracranial extension at the time of surgery. These recurrence rates are similar to those reported by Bremer et al. ${ }^{7}$ Carotid artery occlusions or external carotid artery ligation were not required in any patient. The internal maxillary artery was identified and ligated intra-operatively in all the patients.

Dacrocystorhinostomy was required in 14 patients to deal with post-operative epiphora. Post-operative anterior nasal packing was carried out in all the patients; this was removed five days later.

Of the 8 patients with recurrence, 6 presented in the first two years. Two patients with residual intradural extension were given postoperative radiotherapy (5000 cGy) following which they were symptom free in the follow-up period of three years each. The other 6 underwent further surgery with lateral rhinotomy for excision of the tumor.

The mean volume of intraoperative blood loss in this series was $1200 \mathrm{~mL}$ (range 600$2800 \mathrm{~mL}$ ). The mean volume of blood replacement was $400 \mathrm{ml}$ (range $0-2600 \mathrm{~mL}$ ). Fifteen patients in our series did not require transfusion. In our series, most of the patients were transfused one pint $(350 \mathrm{~mL})$ of blood intraoperatively just before extracting the tumor. Subsequent transfusion was given on the basis of post-operative hemoglobin status.

\section{Complications}

The most common complication in our series was nasal crustation and epiphora. Cheek numbness was observed in 8 patients post operatively. Cosmetic outcome was satisfactory except in 2 patients who developed keloid at the incision site. None of the patients had any ocular or intracranial complication.

\section{Outcome}

All the patients in our series were followed up for at least 12 months post-operatively. Diagnostic nasal endoscopy was performed two months post-operatively in all the cases. There were $8(10 \%)$ recurrences in our series all of which presented in the first two years after initial surgery. No mortality occurred due to the disease or the surgical procedure.

\section{Discussion}

The evolution and refinements in surgical expertise, imaging techniques, ${ }^{8}$ and hypotensive anesthesia have expanded the limits of resectibility of JNA and minimized the complications. A variety of surgical approaches have been described for tumor access. They can be classified primarily as anterior, inferior and lateral skull base approaches. ${ }^{9}$

\section{Point of origin}

The surgical series confirms the finding from other series that the point of origin of JNA is at the superior margin of the sphenopalatine foramen, as described by Harrisson. ${ }^{10}$ From the point of origin, the tumor may extend laterally into the pterygopalatine fossa, infratemporal fossa, ${ }^{6}$ and intracranially or inferiorly into the nasopharynx. ${ }^{11,12}$

\section{Choice of surgical approach}

The principal factors involved in deciding the surgical approach is the point of origin and the extent of the tumor. The approach may also depend on the surgeon's experience with a given technique. The only way to improve the surgical approach is to analyze the results in view of pre-operative extent of the tumor. The inferior skull base approaches are only suitable for resecting stage I and stage II tumors. ${ }^{5}$ The exposure of the infratemporal fossa and lateral skull base is not sufficient for tumor dissection by the inferior approaches in our experience. As such, in our series, the transplataline approach was only adopted in 6 patients with stage I / II tumors.

The lateral skull base approaches provide good exposure of infratemporal fossa and further lateral extension. ${ }^{13}$ However, post-operative hearing loss, mid-face hypoesthesia and long-term temporomandibular joint malfunction limit the routine use of these approaches. ${ }^{14,15}$

\section{Lateral rhinotomy approach}

Lateral rhinotomy is an excellent approach to the tumor as the tumor is directly exposed. Lateral rhinotomy is not an operation but an incision along the side of nose. The incision can be extended down the center of the upper lip when lateral exposure is required beyond

Table 1. Symptoms and signs of juvenile nasopharyngeal angiofibroma in 80 patients.

\begin{tabular}{lcc} 
& N. patients & $\%$ \\
Epistaxis & 72 & 90 \\
Nasal obstruction & 69 & 86.5 \\
\hline Rhinorrhoea & 10 & 12.5 \\
Facial deformity & 12 & 15 \\
\hline Deafness / otalgia & 8 & 10 \\
Palatal bulge & 14 & 17.5 \\
\hline Proptosis & 5 & 6.25 \\
Decreased eye movement & 4 & 5 \\
\hline Others & 20 & 25
\end{tabular}

the infraorbital foramen. ${ }^{16}$ The incision can also be extended in the subciliary region (Weber Fergusson's incision) for better exposure. The tumor can be extracted from the pterygopalatine fossa, infratemporal fossa, and paranasal sinuses by blunt dissection. ${ }^{12}$ Most of the intracranial extensions can also be extracted by gentle traction.

In our series, the cosmetic outcome was satisfactory in all cases. The post-operative scar can be minimized if the incision in taken along the esthetic subunits of the mid-face.

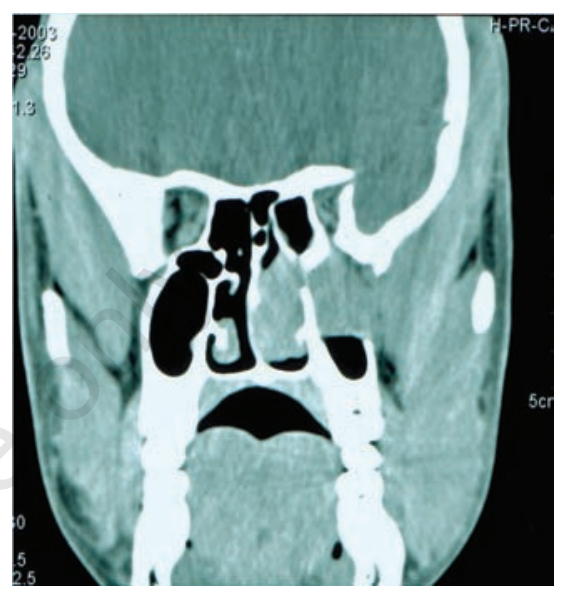

Figure 1. Axial computed tomography of nose and paranxial computed tomography of nose and paranasal sinuses.

Figure 2. Coronal computed tomography nose and paranasal sinuses.

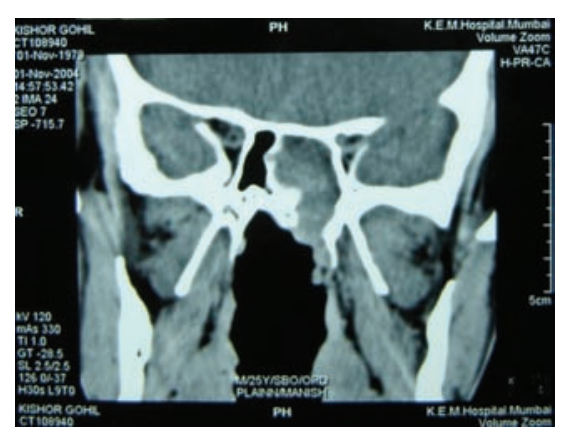


Moreover, the scar is easily camouflaged on account of the brown complexion of Indian males. A small $\mathrm{Z}$ plasty in the region of the medial canthus prevents any webbing.

\section{Recurrence}

In our series there were 8 recurrences (10\%). However, $50 \%$ of these had intracranial extension at the time of initial surgery. All of them presented within two years of surgery with epistaxis. No correlation was found between the age of the patient at the time of surgery and subsequent recurrence. Certain areas were found to have a predilection for recurrence. These include the sphenoid sinus, area of clivus and root of the pterygoids.

\section{Conclusions}

In our experience, the lateral rhinotomy approach not only provides good exposure of the anatomical regions involved by the tumor, but also exposes the tumor adequately, whereby securing hemostasis is easy. At the same time, it also gives satisfactory cosmetic results if the esthetic subunits of the nose and midface are taken into consideration while making the incision. The complications of this approach are also minimal and its greatest advantage is that it can be combined with almost all the other surgical approaches. All the intracranial, extradural extensions in stage IV JNA can be dissected out using this approach. While our preference does not rule out the respective advantages and validity of other surgical approaches, in view of our experience, lateral rhinotomy with its extensions is recommended for surgical excision of juvenile nasopharyngeal angiofibroma.

\section{References}

1. Gullane PJ, Davidson J, O’Dwyer T, Forte V. Juvenile angiofibroma: a review of literature and case series report. Laryngoscope 1992;102:928-83.

2. Mishra SC, Shukla GK, Bhatia N, Panth MC. Angiofibroma of the post nasal space: a critical appraisal of various therapeutic modalities. J Larynol Otol 1991;105:547-52.

3. Scholtz AW, Appenroth E, Kammen-Jolly K, et al. Juvenile nasopharyngeal angiofibroma: management and therapy. Laryngoscope 2001;111:681-7.

4. Tendon DA, Bahadur S, Kacker SK, Goulatia RK. Nasopharyngeal angiofibroma: (a nine-year experience). J Laryngol Otol 1988;102:805-9.

5. Antonelli AR, Cappiello J, Di Lorenzo D, et al. Diagnosis, staging and treatment of juvenile nasopharyngeal angiofibroma (JNA). Laryngoscope 1987;97:1319-25.

6. Fisch U. The infratemporal fossa approach for nasopharyngeal tumors. Laryngoscope 1983;93:36-44.

7. Bremer JW, Neel HB 3rd, DeSanto LW,
Jones GC. Angiofibroma treatment trends in 150 patients during 40 yrs. Laryngoscope 1986;96:1321-8.

8. Lloyd G, Howard D, Lund VJ, Savy L. Imaging of Juvenile angiofibroma. J Laryngol Otol 2000;114:727-30.

9. Mishra SC, Shukla GK, Bhatia N, Panth $\mathrm{MC}$. A rational classification of angiofibroma of the post nasal space. J Laryngol Otol 1989;103:912-6.

10. Harrison DF. The natural history of pathogenesis and treatment of juvenile angiofibroma. Personal experience with 44 patients. Arch Otolaryngol Head Neck Surg 1967:936-42.

11. Howard DJ, Lund VJ. The midfacial degloving approach to sinonasal disease. J Laryngol Otol 1992;106:1059-62.

12. Hiranandani LH. Improved techniques in operative removal of nasopharyngeal fibroma. J Laryngol Otol 1968;82:759-61.

13. Bhatia ML, Mishra SC, Prakash J. Lateral extensions of nasopharyngeal fibroma. J Laryngol Otol 1967;81:99-106.

14. Spector JG. Management of juvenile angiofibromata. Laryngoscope 1988;9:1016 -25 .

15. Herman P, Lot G, Chapot R, et al. Long term follow up Juvenile Nasopharyngeal angiofibroma: Analysis of recurrences. Laryngoscope 1999;109:140-7.

16. Hussein A, Hilimi OJ, Murrary DP. Lateral rhinotomy through aesthetic subunits improved cosmetic outcome. J Laryn Otol 2002;116:703-6. 